\title{
Knowledge, Attitude and Practice of Hypertension among Adult Hypertensive Patients at a Rural Clinic of Coastal Karnataka
}

\author{
Shankar S*, Uttam Kumar*, Sanjay Kini**, Avinash Kumar*** \\ *Post graduate student, Department of Community Medicine, Kasturba Medical College, Manipal \\ **Assistant Professor, Department of Community Medicine, KS Hegde Medical Academy, Mangalore \\ *** Assistant Professor, Department of Community Medicine,Kasturba Medical College, Mangalore
}

\begin{abstract}
:
OBJECTIVE: To study the knowledge, attitude and practice about hypertension in adult hypertensivepatients at a rural clinic of Coastal Karnataka

METHODOLOGY: A study was conducted on five hundred diagnosed hypertensive patients during a one year period in 2013. Patients were questioned by authorized doctors and assessed for various lifestyle and risk factors. A semi-structured pre-tested questionnaire was used to assess socio demographic variables and knowledge, attitude, practices regarding hypertension. Results were analysed using SPSS version 15.

RESULTS: The age of patients ranged from 18 years to 75 years with mean age of 45.5 yearsand median age of 46.5 years. Thirty fourpercent patients belonged to grade 1 education grade,forty sixpercent belonged to grade 2, twelvepercent belonged to grade 3, and eightpercentbelonged to grade $4.13 .4 \%$ patients can explain the hypertension, mostly in higher educationgrade. $75.6 \%$ patients said that salt is not good for hypertension. $50 \%$ patients had good compliance about the drugs. $64.6 \%$ said good controlis advantageous for health. $10 \%$ have knowledge about complications.
\end{abstract}

CONCLUSION: Our study concludes that a significant proportion of hypertensive patient's haveinsufficient knowledge about hypertension.

Key Words:Hypertension, Knowledge, Attitude, Awareness

\section{Introduction}

One of the most important reasons to visit to physician and a major risk factor for Cardiovascular disease worldwide is hypertension which is a silent killer $^{1}$. Increased risk for stroke and various other complications is a result of hypertension ${ }^{2-4}$. Prolonged survival is a result of good control of blood pressure . $^{5-6}$. Morbidity and mortality can be reduced by increasing the knowledge, awareness, and control of hypertension. Many patients did not have appropriate knowledge about hypertension which was evident from various studies?

Special programmers can be conducted to educate uncontrolled hypertensive patients. A standard for the quality of a health care system can also be studied by knowing the burden of hypertension ${ }^{8}$. The insight into the practice pattern of treating hypertension by the physicians can be obtained by study on residents ${ }^{9}$. A considerable difference between evidence based recommendations and actual practice of physicians in managing hypertension in stroke patients is shown by the study conducted on hypertensive strokes ${ }^{10}$. This would require an urgent attention to stress upon the practice of evidence based medicine.

The concept of regular visit to medical persons is unknown to many. In a study conducted in medical students at time of entry test revealed that, out of 179; 52(29.05\%) were hypertensive.On follow up for a long term it was found that only 4(2.24\%) were hypertensive ${ }^{11}$. The Seventh Report of the

Joint National Committee on Prevention, Detection, Evaluation, and Treatment of High Blood Pressure $^{12}$ (JNC-7) says that 50 million Americans were hypertensive (140/90 mm Hg); among them, 70\% know that they are affected, but only $50 \%$ are treated and $25 \%$ controlled $(140 / 90 \mathrm{~mm} \mathrm{Hg})$. Combined home blood pressure monitoring and telephone intervention improved blood pressure control at 24 months relative to usual care which is evident from some studies ${ }^{13}$.

The identification of groups more likely to be unaware can inform the targeting of educationalmessages. Considering the high morbidity and mortality due to hypertension, and knowing that if a patient has knowledge about the disease, patient will be more careful about the management, and a better control can be achieved. This study was conducted to know about knowledge, attitude and practice about hypertension in adult hypertensive patients at a rural clinic in coastal Karnataka.

\section{Methodology}

The study was carried out on five hundred diagnosed hypertensive patients in the year 2013. The study was conducted to assess hypertension knowledge, attitude and practice among hypertensive patients in a rural clinic, to determine whether knowledge of various aspects of hypertension varies among different subgroups. 
Investigators questioned the patients to assess various factors such as lifestyle and risk factors. Reports were prepared, containing all the information as name, age, sex, address, family history, personal history, marital status about the patients. JNC-7 criteria was used for diagnosing hypertension. Blood pressure of 139/89 $\mathrm{mmHg}$ was taken as the upper limit of controlled blood pressure. Uncontrolled blood pressure was considered if it wasabove the upper limit of controlled blood pressure. In diabetics and patients with kidney disease the upper limit for controlled blood pressure was taken as (129/79). The knowledge about hypertension, its control and complications were studied through case sheets containing special questionnaire. To assess this questionnaire education status of patient was divided into four education grades E grade). Education Grade 1: Never gone to school, Education Grade 2: Less than secondary school, Education Grade 3: Secondary school, Education Grade 4: College or more.

Questions asked were: Do you know what is hypertension? Do you know the role of salt intake in hypertension? Mention the compliance about drugs? Describe the advantage of good control? Mention the complications, effect on heart, kidney and brain? Both the urban and rural area patients were taken. In the catchment area various doctors were diagnosing and treating patients. Inclusion criteria were; History of hypertension, and history of taking antihypertensive medicines for at least one month period. Results were analysed using SPSS version 15.

\section{Results}

Five hundred patients were enrolled in this study. $216(43.1 \%)$ patients were females and rest were males. $220(43.9 \%)$ patients were from rural areas and rest were from urban areas. Their ages ranged from 18 years to 75 years with mean age of 45.5 years and median age of 46.5 years. $180(35.9 \%)$ patients were below 40 years of age and remainders were above the age of 40 years. Family history of hypertension was positive in $243(48.6 \%)$ patients. $276(55.2 \%)$ patients were smokers. Thirty fourpercent patients belonged to grade 1 education grade, forty sixpercent belonged to grade2, twelve belonged to grade 3 , and eightpercent belonged to grade $4.13 .4 \%$ patients can explain the hypertension, mostly in higher educationgrade. $75.6 \%$ patients can tell that salt is not good for hypertension. 50\% patients had good compliance about the drugs. $64.6 \%$ can say good control is advantageous for health. 10\% have knowledge about complications. The education grades and result of questionnaire is shown in Table 1

TABLE I: HYPERTENSION: KNOWLEDGE, ATTITUDE AND PRACTICE IN ADULT HYPERTENSIVE PATIENTS E GRADE: EDUATION GRADE

\begin{tabular}{|l|l|l|l|l|}
\hline Questionnaire & E Grade 1 34\% & $\begin{array}{l}\text { E Grade 2 } \\
\mathbf{4 6 \%}\end{array}$ & $\begin{array}{l}\text { E Grade 3 } \\
\mathbf{1 2 \%}\end{array}$ & $\begin{array}{l}\text { E Grade 4 } \\
\mathbf{8 \%}\end{array}$ \\
\hline $\begin{array}{l}\text { Do you know what is } \\
\text { hypertension? }\end{array}$ & $1 \%(2)$ & $76.25 \%(5)$ & $100 \%(60)$ & $90 \%(36)$ \\
\hline $\begin{array}{l}\text { Do you know the role } \\
\text { of salt intake in } \\
\text { hypertension? }\end{array}$ & $60.2 \%(102)$ & $40.6 \%(93)$ & $60.8 \%(36)$ & $100 \%(40)$ \\
\hline $\begin{array}{l}\text { Mention the } \\
\text { compliance about } \\
\text { drugs? }\end{array}$ & $5.38 \%(91)$ & $92.6 \%(213)$ & $75.5 \%(45)$ & $75 \%(30)$ \\
\hline $\begin{array}{l}\text { Describe the advantage } \\
\text { of good control? }\end{array}$ & $14.5 \%(25)$ & $2.1 \%(4)$ & $20 \%(12)$ & $100 \%(40)$ \\
\hline $\begin{array}{l}\text { Mention the } \\
\text { complications, effect } \\
\text { on heart, kidney and } \\
\text { brain? }\end{array}$ & $2.04 \%(10)$ & & $60 \%(24)$ \\
\hline
\end{tabular}

\section{Discussion}

From various studies conducted in the western countries it was seen that $82 \%$ know the meaningof hypertension, while $90 \%$ high blood pressure patients know that normalization of blood pressure will improve their health status ${ }^{16}$. Blood pressure levels were unknown to most of the admitted cardiac patients. Analysis regarding knowledge, control and complications of hypertension was carried out by us. Educated people (Education grade 4) had better understanding of hypertension than patients who were less educated (Education grade 3 and less). The complications of blood pressure were more effectively understood by patients with Grade 4 education. More educated (E grade 4) patients were able to report that they had received information regarding ideal blood pressure values compared to less educatedpatients (E grade 3 and less) which was evident from the present study. In our study twenty percent patients reported that a physician or otherhealth care provider was a source of information about high blood pressure. Television, newspapers, magazines, and radio were sources for information for ten percent of patients. Almost 30\% people got information about blood pressure from near relatives in one of the studies ${ }^{17}$. Only a fraction of individuals $69.1 \%$ hospitalized with ischemic heart disease know about blood pressure values in one of the studies ${ }^{18}$. A study carried out at Karachi's low income 
settlements showed that the overall prevalence of hypertension was $26 \%$, in males it was $34 \%$ and in females it was $24 \%$ and it has been further studied that specially trained general practitioners in management of hypertension, provide better doctor-patient relationship and it is more effective in providing good control of blood pressure. For the states having increased burden of hypertensive cases similar efforts are required ${ }^{19}$. In one of the studies those who were 65 years of age or above had increasing difficulty of controlling blood pressure where as young patients were more aware about hypertension and received treatment ${ }^{20}$. Hypertension is a common risk factor for cardiovasculardisease and awareness, treatment, and control of hypertension are comparable to the best rates ${ }^{21}$. The frequency of high cholesterol level is about $60 \%$ of hypertensive patients in our population and it is seen that hypertension and hypercholesterolemia are important modifiable risk factors for ischemic heart disease ${ }^{22}$. About $22.1 \%$ people are hypertensive in India and $20 \%$ know about the disease and receive the treatment ${ }^{23}$.Having a good control of hypertension is of vital importance. Improvement in parental ratings of executive function occurs after 12 months of anti-hypertensive therapy as evident from a study on children with hypertension byLandeM et $\mathrm{al}^{24}$. Educational campaigns are required to improve knowledge in our population which is insufficient and partly associated with educational level, leaving much room for improvement. Undiagnosed, untreated, and uncontrolled hypertensionclearly places a substantial strain on the health care delivery system. Large benefits can be achieved by specially trained medical personals.

\section{References}

[1]. Lewington S, Clarke R, Qizilbash N, PetoR,Collins R. Prospective Studies Collaboration. Age specific relevance of usual blood pressure to vascular mortality: a meta-analysis of individual datafor one million adults in 61 prospective studies. Lancet. 2002 Dec 14;360:1903-13

[2]. Wang J, Staessen J, Franklin S, Fagard R, GueyffierF. Systolic and diastolic blood pressure lowering as determinants of cardiovascular outcome. Hypertension. 2005;45:907-13.

[3]. Chobanian A, Bakris G, Black H Cushman W. The seventh report of the joint national committee onprevention, detection, evaluation, and treatment of high blood pressure: the JNC 7 report. JAMA.2003 21;289:2560-72.

[4]. Stamler J, Stamler R, Neaton J. Blood pressure, systolic and diastolic, and cardiovascular risks.U.S. population data. Arch 4. Intern Med. 1993; 53:598-615.

[5]. Vasan R, Larson M, Leip E, Evans J. Impact of high-normal blood pressure on the risk of cardiovascular disease. N Engl J Med. 2001; 345:1291-7.

[6]. Terry D, Pencina M, Vasan R, Murabito J. Cardiovascular risk factors predictive for survival andmorbidity-free 6. survival in the oldest-old Framingham Heart Study participants. J Am GeriatrSoc. 2005; 53:1944-50.

[7]. Susan A, Roland S, Bruce D, Catherine, Martha N. Hypertension Knowledge, Awareness, and Attitudes in a Hypertensive Population. J Gen Intern Med. 2005; 20: 219-225.

[8]. Peter B, Michael B, Massimo V, Bobby V. A Global Perspective on Blood Pressure Treatmentand Control in a Referred Cohort of Hypertensive Patients. The Journal of Clinical Hypertension.2010: 12,666-677.

[9]. Robert N, Robin G, Kyle P, Julie E. Attitudes and Practices of Resident Physicians Regarding Hypertension in the Inpatient Setting. The Journal of Clinical Hypertension. 2010: 12; 698-705.

[10]. NaveedaK,Nausheen H, Rabia A, Mobeen I. Knowledge and perceptions of physicians aboutEvidence Based Management of hypertension in acute ischemic stroke patients.Rawal Med J2010;35:51-53.

[11]. Talat N, Nabeel A, Naureen, A. Prevalence of Hypertensionmanagement interventions to improve hypertension control: a randomized trial. Ann Intern Med. 2009;151:687-95.

[12]. Chobanian A, Bakris G, Black H, Cushman W, Green L, Izzo J, et al. The Seventh Report of theJoint National Committee on Prevention, Detection, Evaluation, and Treatment of High BloodPressure. JAMA 2003; 289: 2560.

[13]. Bosworth H, Olsen M, Grubber J. Two self-management interventions to improve hypertensioncontrol: a randomized trial. Ann Intern Med. 2009;151:687-95.

[14]. Anthony J, Lauren W, Madeline M, Philip D. High Blood Pressure Knowledge Among Primary Care Patients with Known Hypertension: A North Carolina Family Medicine Research Network (NC-FMRN) Study. The Journal of the American Board of Family Medicine.2008; 21: 300-308.

[15]. h t t p : / /www.nh 1 b i.nih.gov/about/nhbpep/ nhbp_pd.htm. Klein R J, Schoenborn CA. NationalHeart Lung and Blood Institute.National High Blood Pressure Education Program. Accessed on1.9.2010.

[16]. Oliveria S, Chen R, McCarthy B, Davis C, Hill M. Hypertension knowledge, awareness, and attitudesin a hypertensive population. J Gen Intern Med 2005; 20: 219-25.

[17]. Sharon B, ErmegL., Marion R, Sean A, Evelyn R, Michael E, et al. Prevalence, Awareness, Treatment, and Control of Hypertension in the Jackson Heart Study. http://hyper.ahajournals.org/cgi/reprint/ Hypertension published online Feb 11,2008.

[18]. Cheng S, LichmanH, Amatruda M, Smith L, MatteraA, Roumanis A, et;al. Knowledge of bloodpressure levels and targets in patients with coronaryamongst young, students at the time ofentry in a Medical College of Punjab. Pak J Cardiol. 2001; 12:57-60.

[19]. Safdar S, Omair A, Faisal U, Hasan H. Prevalence of Hypertension in a low income settlementof Karachi, Pakistan. JPMA 2004; 54: 506-9.

[20]. Nudrat N, Juanita H. Effect of general practitioner education on adherence to antihypertensivedrugs: cluster randomized controlled trial. BMJ 2007; 335:1030.

[21]. Efstratopoulos A, Voyaki S, Baltas A, Vratsistas F, Kirlas D, Kontoyannis J, et al. Prevalence,awareness, treatment and control of hypertension in Hellas,Greece: the Hypertension Study inGeneral Practice in Hellas (HYPERTENSHELL) national study. Am J Hypertens .2006;19:53-60.

[22]. Shaikh M. A, QazI R. Hyperchlesterolemia in hypertensive patients.APIMS.2005; 1: 142-5.

[23]. Jonas J, Nangia V, Matin A, Joshi P, Ughade S. Prevalence, awareness, control, and associationsof arterial hypertension in a rural central India population: the Central India Eye and Medical Study. Am J Hypertens 2010;23:347-50.

[24]. Lande M, Adams H, Falkner B. Parental assessment of executive function and internalizing andexternalizingbehavior in primary hypertension after anti-hypertensive therapy. J.Pediatr.2010;157:114-9. 